\title{
All cause mortality and the case for age specific alcohol consumption guidelines: pooled analyses of up to 10 population based cohorts
}

\author{
Craig S Knott, ${ }^{1}$ Ngaire Coombs, ${ }^{2,3}$ Emmanuel Stamatakis, ${ }^{2,4,5}$ Jane P Biddulph
}

${ }^{1}$ Department of Epidemiology and Public Health, University

College London, London, UK 2Physical Activity Research Group, Department of Epidemiology and Public Health, University College London, London, UK

${ }^{3}$ Department of Social Statistics and Demography, University of Southampton, Southampton, UK

${ }^{4}$ Charles Perkins Centre, University of Sydney, Sydney, Australia

${ }^{5}$ Exercise Health and

Performance Faculty Research

Group, Faculty of Health

Sciences, University of Sydney,

Sydney, Australia

Correspondence to:

CS Knott craig.knott.10@ucl.ac.uk Additional material is published online only. To view please visit the journal online (http:// dx.doi.org/10.1136/BMJ.h384) Cite this as: $B M J$ J 2015;350:h384 doi: 10.1136/bmj.h384

Accepted: 2 December 2014

\section{ABSTRACT}

\section{OBJECTIVES}

To examine the suitability of age specific limits for alcohol consumption and to explore the association between alcohol consumption and mortality in different age groups.

DESIGN

Population based data from Health Survey for England 1998-2008, linked to national mortality registration data and pooled for analysis using proportional hazards regression. Analyses were stratified by sex and age group (50-64 and $\geq 65$ years).

\section{SETTING}

Up to 10 waves of the Health Survey for England, which samples the non-institutionalised general population resident in England.

\section{PARTICIPANTS}

The derivation of two analytical samples was based on the availability of comparable alcohol consumption data, covariate data, and linked mortality data among adults aged 50 years or more. Two samples were used, each utilising a different variable for alcohol usage: self reported average weekly consumption over the past year and self reported consumption on the heaviest day in the past week. In fully adjusted analyses, the former sample comprised Health Survey for England years 1998-2002, 18368 participants, and 4102 deaths over a median follow-up of 9.7 years, whereas the latter comprised Health Survey for England years 1999-2008, 34523 participants, and 4220 deaths over a median follow-up of 6.5 years.

\section{WHAT IS ALREADY KNOWN ON THIS TOPIC}

Alcohol intake is increasing among people aged $\geq 65$ years and, in conjunction with greater morbidity and prescription drug use, this age group is at risk of alcohol related problems because of impaired metabolism of alcohol with age

Meta-analyses of observational data repeatedly indicate that, compared with non-drinkers, moderate consumption may be protective against cardiovascular diseases and all cause mortality

It is unclear from existing evidence whether the protective effect of moderate alcohol consumption is both real and applicable to older populations

\section{WHAT THIS STUDY ADDS}

Data from up to 10 cohorts representative of the English population, suggest that previous associations indicating a protective effect between alcohol intake and all cause mortality may have been partly attributable to inappropriate selection of the referent group and weak adjustment for confounders

When compared with self reported never drinkers, protective associations were largely limited to women drinkers aged 65 years or more

Little to no protection was present in other age-sex groups

\section{MAIN OUTCOME MEASURE}

All cause mortality, defined as any death recorded between the date of interview and the end of data linkage on 31 March 2011.

\section{RESULTS}

In unadjusted models, protective effects were identified across a broad range of alcohol usage in all age-sex groups. These effects were attenuated across most use categories on adjustment for a range of personal, socioeconomic, and lifestyle factors. After the exclusion of former drinkers, these effects were further attenuated. Compared with self reported never drinkers, significant protective associations were limited to younger men (50-64 years) and older women ( $\geq 65$ years). Among younger men, the range of protective effects was minimal, with a significant reduction in hazards present only among those who reported consuming 15.1-20.0 units/average week (hazard ratio 0.49, 95\% confidence interval 0.26 to 0.91 ) or $0.1-1.5$ units on the heaviest day $(0.43,0.21$ to 0.87$)$. The range of protective effects was broader but lower among older women, with significant reductions in hazards present $\leq 10.0$ units/average week and across all levels of heaviest day use. Supplementary analyses found that most protective effects disappeared where calculated in comparison with various definitions of occasional drinkers.

\section{CONCLUSIONS}

Beneficial associations between low intensity alcohol consumption and all cause mortality may in part be attributable to inappropriate selection of a referent group and weak adjustment for confounders. Compared with never drinkers, age stratified analyses suggest that beneficial dose-response relations between alcohol consumption and all cause mortality may be largely specific to women drinkers aged 65 years or more, with little to no protection present in other age-sex groups. These protective associations may, however, be explained by the effect of selection biases across age-sex strata.

\section{Introduction}

High alcohol consumption has been negatively associated with more than 200 acute and chronic conditions, ${ }^{1-2}$ with direct healthcare costs estimated to account for $€ 2.7 \mathrm{bn}$ (\$4.1bn; $€ 3.6 \mathrm{bn}$ ) of annual National Health Service expenditure in England in 2006-07, ${ }^{3}$ and $£ 3.5$ bn by $2011-12^{4}$-around $3 \%$ of the annual healthcare budget. ${ }^{5}$ Inclusive of social costs such as losses to labour productivity, estimates increase approximately 10 -fold to between $£ 20 \mathrm{bn}^{6}$ and $£ 55$ bn per annum. ${ }^{7}$ 
Studies examining the relation between alcohol consumption and all cause mortality have identified J-shaped associations, which suggest that low alcohol consumption may confer some degree of protection. ${ }^{8}$ Compared with non-drinkers, data pooled from 16 cohort studies have shown a reduction in risk at lower levels of alcohol consumption among both men and women at a daily use of $\leq 1.9$ US standard drinks, ${ }^{8}$ equivalent to $\leq 26.6 \mathrm{~g}$ of ethanol or $\leq 3.3 \mathrm{UK}$ units/day. ${ }^{9}$ Peak risk reduction occurred at 1.0-1.9 standard drinks per day (1.8-3.4 units/day) in men (relative risk 0.84, $95 \%$ confidence interval 0.82 to 0.86 ) and $0.1-0.9$ standard drinks (0.2-1.6 units/day) among women (0.88, 0.86 to 0.90$).{ }^{8}$ More recently, data from 34 cohort studies showed peak protection at lower levels: a 17\% (95\% confidence interval $15 \%$ to $19 \%$ ) reduction at $6 \mathrm{~g} /$ day ( 0.8 units/day) among men, and an 18\% (13\% to 22\%) reduction at $5 \mathrm{~g} /$ day ( 0.6 units/day) among women. ${ }^{10}$ Here, protective effects were present $\leq 38 \mathrm{~g} /$ day $(\leq 4.8$ UK units/day) among men and $\leq 18 \mathrm{~g} /$ day $(\leq 2.3$ UK units/day) among women. It is possible that the J-shaped association between alcohol consumption and all cause mortality may be in part a product of a similarly protective relation between alcohol and vascular diseases, ${ }^{11,12}$ with circulatory conditions representing 29\% (124 442/427170) of deaths in 2013 among people aged 65 years or more and living in England and Wales-the largest proportion of any reported group of conditions. ${ }^{13}$

The J-shaped relation is contentious, however, with some arguing that protective effects may be confounded by the common classification of heterogeneous non-drinking groups into a single referent category. ${ }^{14-16}$ Specifically, former drinkers have been found to exhibit poorer self reported health, ${ }^{17}$ higher levels of depression, ${ }^{18}$ and increased risk of mortality than never drinkers. ${ }^{19}$ As such, protective associations identified among light drinkers may be less a consequence of a beneficial biological mechanism and more a statistical artefact resulting from the application of a pooled non-drinking category. Indeed, when former drinkers were excluded from meta-analysis, ${ }^{10}$ the protective effect between alcohol consumption and total mortality was attenuated $(\mathrm{P}<0.01)$. Such a finding suggests that protective effects may have been over-estimated by existing studies.

Beside the selection of a more appropriate referent group, the part played by age is often overlooked by research into alcohol related mortality. According to data from the Health Survey for England, consumption in excess of recommended daily limits has increased among older age groups. ${ }^{20}$ Between 1994 and 2012, consumption in excess of recommended daily limits among people aged $65-74$ years increased from $5.3 \%$ to $14.0 \%$, and from $6.0 \%$ to $14.8 \%$ in those aged 75 years or more, with increases greatest among women in absolute and relative terms.

Physiological changes to the aging body are understood to adversely affect the timely elimination of blood ethanol after consumption, with decreases in body water, hepatic function, and blood flow all implicated. $^{21-24}$ Given the increased duration and peak con- centration of blood ethanol that may be experienced by drinkers of advancing age, increasing consumption among older populations presents an area of potential public health concern. This is especially so given age related increases in morbidities known to be worsened in response to alcohol use, ${ }^{25}$ as well as age related increases in the use of prescription drugs potentially contraindicated with alcohol. ${ }^{26-28}$ Although potentially the product of a lag effect from drinking over the limits earlier in life, the number of alcohol related hospital admissions and wholly attributable deaths are greatest among older age groups. ${ }^{29}$

Taken together, such factors suggest that older populations may benefit most from a reduction in alcohol consumption. In response, the UK Royal College of Psychiatrists recently advised a reduction in the recommended limits for those aged 65 years or more, from 21 units (about $165.9 \mathrm{~g}$ of ethanol) per week for men and 14 units (110.6 g) per week for women, to 11 units (86.9 g) per week or 1.5 units per day for both men and women aged 65 years or more. ${ }^{30}$ Evidence underpinning such an age specific threshold is, however, lacking.

Although it is common to stratify dose-risk estimates by sex, age is often included only as a confounding factor. Of the 34 mortality studies eligible for a meta-analysis, ${ }^{10}$ just two publications included participants aged 65 years or more and reported results by age group. The first, a study of Hawaiian men of Japanese origin aged 51-64 ( $\mathrm{n}=2946)$ and 65-75 $(\mathrm{n}=847)$ years, found no significant multivariate adjusted relation between alcohol consumption and all cause mortality in either age group after six years, although J-shaped relations were visible in each age group compared with pooled non-drinkers. ${ }^{31}$ The second study, which used data from the first US National Health and Examination Survey (NHANES I) and benefited from a larger sample and follow-up period, stratified results by people aged 25-59 years and 60-75 years and adjusted for age, education, smoking status, and body mass index. ${ }^{32}$ Middle aged men and women drinkers showed no significant difference in all cause mortality compared with non-drinkers, except at very high levels of consumption, where risks were increased. In contrast, older men and women each exhibited marginally protective associations at less than two standard US drinks a week ( $<0.5$ units/day), with odds ratios of 0.78 ( $95 \%$ confidence interval 0.61 to 1.00 ) and 0.82 (0.67 to 1.00), respectively. Although a protective effect was identified up to higher levels of consumption in other models, these accounted for factors potentially present on the causal pathway, such as cholesterol ${ }^{33}$ and blood pressure. ${ }^{34}$ Beyond these two publications, there is some suggestion that any protective effect conferred by alcohol may be greatest among older populations, ${ }^{35}$ potentially supporting the hypothesis of reduced mortality occurring through a beneficial effect of alcohol consumption on cardiovascular morbidities prevalent among older populations.

Given the lack of age-specific data, ${ }^{10}$ we explored the association between alcohol consumption and all cause mortality for people aged less than 65 years and aged 65 or more. In addition, we examined the effect of adopting 
an improved choice of referent group by separating never drinkers and former drinkers. We hypothesised that if the protective effect of moderate drinking was more than an artefact of study design and operated through a cardiovascular pathway, any risk reduction in mortality would be greatest among those aged 65 years or more.

\section{Methods \\ Participants}

The Health Survey for England is an annual, nationally representative cross sectional survey of the non-institutionalised general population resident in England. Since 1994, adult participants have been asked for consent to follow-up through linkage to national mortality registration data, making possible the longitudinal analysis of survival rates within population subgroups. Detailed information on the Health Survey for England has been published elsewhere. ${ }^{36}$

The derivation of analytical samples in this study was based on the availability of comparable data on alcohol consumption, covariate data, and linked mortality data among adults aged 50 years or more (fig 1 ). We excluded those aged less than 50 years to reduce the possibility of dilution of the hazard ratios within the subgroup of younger adults. We also performed sensitivity analyses and included those aged less than 50 years (see supplementary tables 1 and 2). In the fully adjusted models, truncation of the sample significantly increased protective associations observed among men. Protective associations also increased among women, but were broadly comparable in effect size.

We derived two analytical samples according to different alcohol use variables: self reported average weekly consumption over the past year and self reported consumption on the heaviest day in the past week. In fully adjusted analyses, the former sample comprised Health Survey for England years 1998-2002, 18368 participants, and 4102 deaths over a median follow-up of 9.7 years, whereas the latter concerned Health Survey for England years 1999-2008, 34523 participants, and 4220 deaths over a median 6.5 years of follow-up (fig 1).

\section{Outcome variable}

We defined all cause mortality as any death recorded between baseline and the end of linkage on 31 March 2011. Mortality was coded as a binary variable representing death or censoring. Analyses were restricted to those who consented to linkage. Those who consented were more likely to be younger, in higher socioeconomic positions, have higher educational attainment, and be of white ethnic background.

\section{Alcohol consumption}

Figure 2 shows the derivation of the alcohol use categories. In all years, participants were asked whether they "ever drink alcohol nowadays," including drinks brewed or made at home or consumed for special occasions. Former drinkers comprised those who reported consuming alcohol in the past but had since stopped drinking, and never drinkers were those who reported never having consumed alcohol.

\section{Average weekly consumption}

Those who reported having consumed alcohol in the past year were asked about their frequency of consumption over the past 12 months. Of those who responded, supplementary questions were posed for six different drink types: normal strength beer/lager/ stout/cider/shandy; strong beer/lager/cider; wine; sherry and martini; spirits and liqueurs; alcoholic soft drinks. Participants were also asked about the quantity "usually drunk on any one day" according to drink

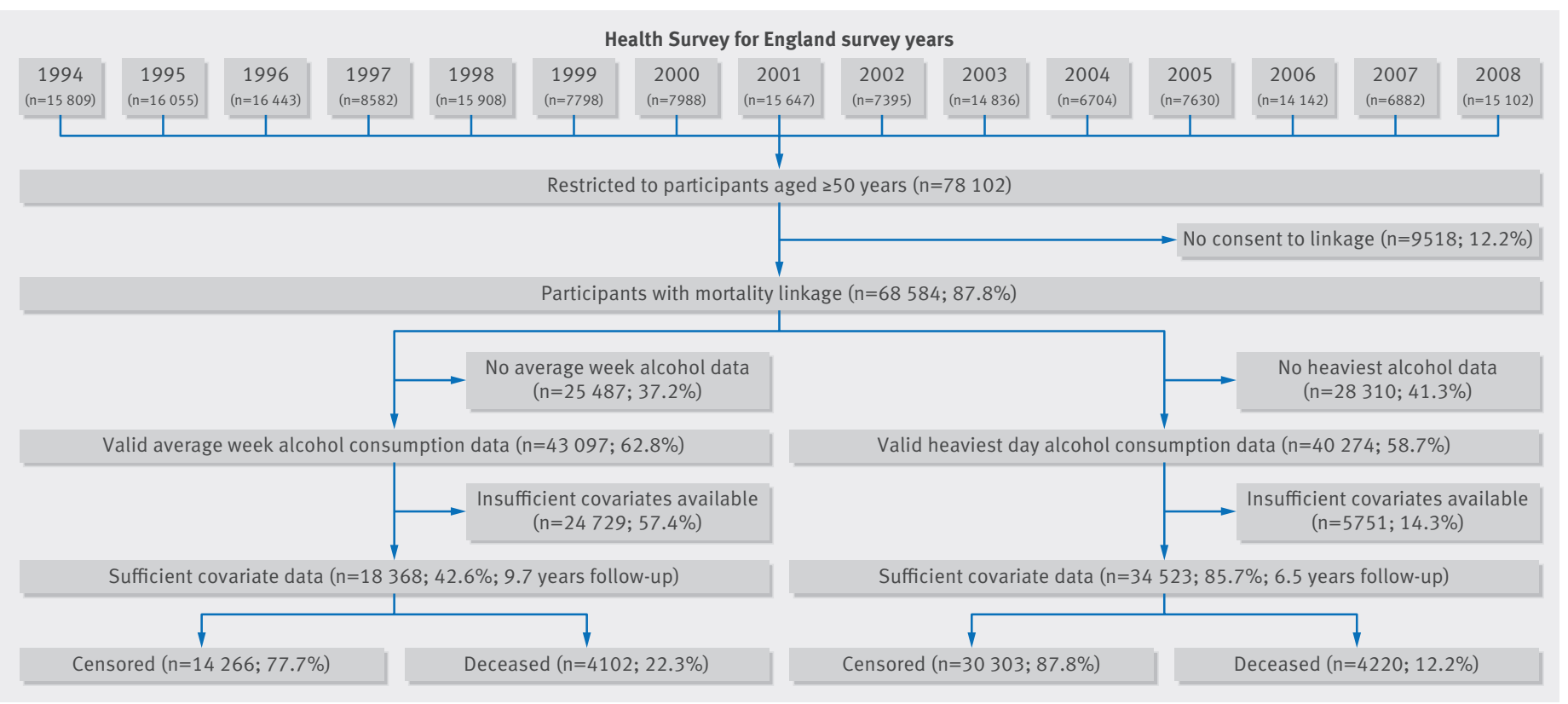

Fig 1 | Derivation of the analytical samples 


\begin{tabular}{|c|c|c|c|c|c|c|}
\hline \multirow[b]{2}{*}{ Alcohol intake } & \multicolumn{3}{|l|}{$50-64$ years } & \multicolumn{3}{|l|}{$\geq 65$ years } \\
\hline & No of deaths & Hazard ratio $(95 \% \mathrm{Cl})$ & Pvalue & No of deaths & Hazard ratio $(95 \% \mathrm{Cl})$ & $P$ value \\
\hline \multicolumn{7}{|c|}{ Weekly consumption (1998-2002) } \\
\hline \multicolumn{7}{|l|}{ Model 1:* } \\
\hline Non-drinker & 60 & 1.00 (reference) & & 307 & 1.00 (reference) & \\
\hline Not in past 12 monthst & 2 & $0.87(0.21$ to 3.57$)$ & 0.85 & 19 & $1.18(0.74$ to 1.87$)$ & 0.49 \\
\hline$<1$ occasion/month & 53 & 0.66 (0.46 to 0.95$)$ & 0.03 & 268 & $0.82(0.70$ to 0.97$)$ & 0.02 \\
\hline 1-2 occasions/month & 48 & $0.59(0.40$ to 0.86$)$ & 0.01 & 180 & 0.75 (0.62 to 0.90$)$ & $<0.01$ \\
\hline $0.1-5.0$ units & 51 & $0.58(0.40$ to 0.84$)$ & $<0.01$ & 328 & 0.80 (0.68 to 0.93$)$ & 0.01 \\
\hline $5.1-10.0$ units & 72 & $0.54(0.38$ to 0.76$)$ & $<0.01$ & 328 & 0.64 (0.54 to 0.74$)$ & $<0.01$ \\
\hline $10.1-15.0$ units & 58 & 0.52 (0.37 to 0.75$)$ & $<0.01$ & 226 & 0.77 (0.65 to 0.92$)$ & $<0.01$ \\
\hline $15.1-20.0$ units & 34 & $0.41(0.27$ to 0.62$)$ & $<0.01$ & 108 & 0.60 (0.48 to 0.75$)$ & $<0.01$ \\
\hline$>20.0$ units & 195 & 0.69 (0.51 to 0.92$)$ & 0.01 & 413 & $0.74(0.63$ to 0.85$)$ & $<0.01$ \\
\hline \multicolumn{7}{|l|}{ Model 2:‡ } \\
\hline Non-drinker & 54 & 1.00 (reference) & & 217 & 1.00 (reference) & \\
\hline Not in past 12 months $\dagger$ & 1 & $0.53(0.07$ to 3.90$)$ & 0.53 & 11 & 1.28 (0.69 to 2.36$)$ & 0.43 \\
\hline$<1$ occasion/month & 45 & $0.63(0.42$ to 0.94$)$ & 0.02 & 203 & 0.81 (0.67 to 0.98$)$ & 0.03 \\
\hline 1-2 occasions/month & 41 & 0.61 (0.40 to 0.93$)$ & 0.02 & 141 & 0.79 (0.64 to 0.98$)$ & 0.03 \\
\hline $0.1-5.0$ units & 44 & $0.75(0.50$ to 1.14$)$ & 0.18 & 249 & $0.82(0.68$ to 0.99$)$ & 0.04 \\
\hline $5.1-10.0$ units & 65 & $0.66(0.45$ to 0.97$)$ & 0.03 & 263 & $0.70(0.58$ to 0.84$)$ & $<0.01$ \\
\hline $10.1-15.0$ units & 52 & 0.65 (0.44 to 0.97$)$ & 0.03 & 188 & 0.82 (0.67 to 1.00$)$ & 0.06 \\
\hline $15.1-20.0$ units & 30 & $0.51(0.32$ to 0.82$)$ & 0.01 & 83 & $0.69(0.53$ to 0.89$)$ & 0.01 \\
\hline$>20.0$ units & 175 & 0.75 (0.54 to 1.03$)$ & 0.08 & 341 & 0.79 (0.66 to 0.94$)$ & 0.01 \\
\hline \multicolumn{7}{|c|}{ Consumption on heaviest day (1999-2008) } \\
\hline \multicolumn{7}{|l|}{ Model 1:* } \\
\hline Non-drinker & 57 & 1.00 (reference) & & 309 & 1.00 (reference) & \\
\hline Not in past 12 monthst & 6 & $2.26(0.97$ to 5.24$)$ & 0.06 & 26 & 1.06 (0.71 to 1.58$)$ & 0.78 \\
\hline$<1$ occasion/month & 57 & 0.69 (0.48 to 0.99$)$ & 0.05 & 357 & 0.93 (0.80 to 1.08$)$ & 0.34 \\
\hline 1-2 occasions/month & 44 & 0.53 (0.36 to 0.79$)$ & $<0.01$ & 216 & $0.79(0.67$ to 0.95$)$ & 0.01 \\
\hline > 2 occasions/month§ & 20 & 0.65 (0.39 to 1.09$)$ & 0.10 & 130 & $0.90(0.73$ to 1.11$)$ & 0.32 \\
\hline $0.1-1.5$ units & 29 & $0.33(0.21$ to 0.52$)$ & $<0.01$ & 427 & 0.71 (0.61 to 0.82 ) & $<0.01$ \\
\hline $1.6-3.0$ units & 88 & 0.49 (0.35 to 0.68$)$ & $<0.01$ & 454 & 0.68 (0.59 to 0.78$)$ & $<0.01$ \\
\hline $3.1-4.5$ units & 64 & 0.68 (0.48 to 0.97 ) & 0.04 & 201 & 0.82 (0.68 to 0.98 ) & 0.03 \\
\hline$>4.5$ units & 214 & $0.67(0.50$ to 0.90$)$ & 0.01 & 298 & 0.69 (0.59 to 0.81$)$ & $<0.01$ \\
\hline \multicolumn{7}{|l|}{ Model 2: } \\
\hline Non-drinker & 42 & 1.00 (reference) & & 215 & 1.00 (reference) & \\
\hline Not in past 12 monthst & 4 & 1.77 (0.63 to 5.03$)$ & 0.28 & 19 & 1.10 (0.69 to 1.76$)$ & 0.69 \\
\hline$<1$ occasion/month & 46 & 0.66 (0.43 to 1.01$)$ & 0.06 & 269 & 0.90 (0.75 to 1.09$)$ & 0.28 \\
\hline 1-2 occasions/month & 39 & 0.66 (0.42 to 1.03$)$ & 0.07 & 167 & $0.86(0.70$ to 1.06$)$ & 0.15 \\
\hline$>2$ occasions/month§ & 18 & 0.78 (0.44 to 1.36$)$ & 0.38 & 92 & 0.85 (0.67 to 1.09 ) & 0.21 \\
\hline $0.1-1.5$ units & 25 & 0.50 (0.30 to 0.84$)$ & 0.01 & 322 & 0.78 (0.65 to 0.93$)$ & 0.01 \\
\hline $1.6-3.0$ units & 76 & 0.69 (0.47 to 1.02$)$ & 0.06 & 351 & 0.73 (0.61 to 0.87 ) & $<0.01$ \\
\hline $3.1-4.5$ units & 54 & 0.84 (0.56 to 1.27$)$ & 0.40 & 169 & 0.90 (0.73 to 1.10$)$ & 0.30 \\
\hline$>4.5$ units & 198 & 0.83 (0.59 to 1.18$)$ & 0.30 & 248 & $0.68(0.57$ to 0.82$)$ & $<0.01$ \\
\hline \multicolumn{7}{|l|}{ Sample sizes (weekly): } \\
\hline Model 1 & & 5308 & & & 4447 & \\
\hline Model 2 & & 4876 & & & 3755 & \\
\hline \multicolumn{7}{|l|}{ Sample sizes (heaviest day): } \\
\hline Model 1 & & 10046 & & & 8365 & \\
\hline Model 2 & & 9155 & & & 7096 & \\
\hline
\end{tabular}

*Adjusted for age.

tParticipants who reported being current drinkers and also reported not having consumed alcohol within the 12 months before interview.

¥As model 1, plus adjustment for body mass index, economic activity, education, ethnicity, government office region, marital status, smoking status, and social class.

§Participants who reported an average annual frequency of $>2$ occasions/month but who reported not drinking in the week before interview.

sizes such as pints, bottles, and $125 \mathrm{ml}$ glasses. An estimate of weekly consumption was then derived by converting reported quantities into UK units of alcohol according to assumed average drink strengths, then multiplying the units by the average number of drinking days a week, as based on reported consumption frequency over the preceding 12 months. The weekly use variable was then recoded into five categories:
0.1-5, 5.1-10, 10.1-15, 15.1-20, > 20 units/week. (See the 2002 Health Survey for England report for further information on the precise conversion factors used for the derivation of a weekly alcohol consumption variable. ${ }^{37}$ ) Additional categories included those who defined themselves as current drinkers but did not consume alcohol in the year before being interviewed by Health Survey for England staff, and frequency 


\begin{tabular}{|c|c|c|c|c|c|c|}
\hline \multirow[b]{2}{*}{ Alcohol intake } & \multicolumn{3}{|l|}{$50-64$ years } & \multicolumn{3}{|l|}{$\geq 65$ years } \\
\hline & No of deaths & Hazard ratio $(95 \% \mathrm{Cl})$ & $P$ value & No of deaths & Hazard ratio $(95 \% \mathrm{Cl})$ & P value \\
\hline \multicolumn{7}{|c|}{ Weekly consumption (1998-2002) } \\
\hline \multicolumn{7}{|l|}{ Model 1:* } \\
\hline Non-drinker & 72 & 1.00 (reference) & & 653 & 1.00 (reference) & \\
\hline Not in past 12 monthst & 7 & 1.37 (0.63 to 2.98$)$ & 0.43 & 26 & $1.33(0.90$ to 1.96$)$ & 0.16 \\
\hline$<1$ occasion/month & 81 & 0.78 (0.57 to 1.08$)$ & 0.14 & 511 & $0.79(0.70$ to 0.89$)$ & $<0.01$ \\
\hline 1-2 occasions/month & 52 & $0.59(0.42$ to 0.85$)$ & $<0.01$ & 220 & 0.63 (0.54 to 0.73$)$ & $<0.01$ \\
\hline $0.1-5.0$ units & 66 & 0.55 (0.39 to 0.76$)$ & $<0.01$ & 364 & 0.65 (0.57 to 0.74$)$ & $<0.01$ \\
\hline $5.1-10.0$ units & 50 & $0.52(0.36$ to 0.74$)$ & $<0.01$ & 276 & 0.73 (0.63 to 0.84$)$ & $<0.01$ \\
\hline $10.1-15.0$ units & 25 & 0.43 (0.27 to 0.67$)$ & $<0.01$ & 116 & 0.67 (0.55 to 0.82$)$ & $<0.01$ \\
\hline $15.1-20.0$ units & 15 & 0.54 (0.31 to 0.95$)$ & 0.03 & 43 & 0.60 (0.44 to 0.81$)$ & $<0.01$ \\
\hline$>20.0$ units & 37 & 0.76 (0.51 to 1.13$)$ & 0.17 & 94 & 0.73 (0.59 to 0.90$)$ & $<0.01$ \\
\hline \multicolumn{7}{|l|}{ Model 2: } \\
\hline Non-drinker & 56 & 1.00 (reference) & & 386 & 1.00 (reference) & \\
\hline Not in past 12 months $\dagger$ & 6 & $1.16(0.49$ to 2.71$)$ & 0.74 & 16 & 1.57 (0.94 to 2.61) & 0.08 \\
\hline$<1$ occasion/month & 67 & 0.70 (0.49 to 1.00$)$ & 0.05 & 339 & 0.76 (0.65 to 0.88$)$ & $<0.01$ \\
\hline 1-2 occasions/month & 42 & 0.65 (0.43 to 0.97$)$ & 0.04 & 160 & 0.67 (0.56 to 0.81$)$ & $<0.01$ \\
\hline $0.1-5.0$ units & 60 & 0.69 (0.47 to 1.00$)$ & 0.05 & 265 & 0.70 (0.60 to 0.82$)$ & $<0.01$ \\
\hline $5.1-10.0$ units & 47 & 0.61 (0.41 to 0.91$)$ & 0.02 & 187 & 0.70 (0.58 to 0.83$)$ & $<0.01$ \\
\hline $10.1-15.0$ units & 22 & 0.48 (0.29 to 0.79$)$ & $<0.01$ & 89 & 0.77 (0.61 to 0.98$)$ & 0.03 \\
\hline $15.1-20.0$ units & 14 & $0.71(0.39$ to 1.29$)$ & 0.26 & 37 & 0.67 (0.48 to 0.94$)$ & 0.02 \\
\hline$>20.0$ units & 32 & 0.77 (0.49 to 1.20$)$ & 0.25 & 74 & 0.71 (0.55 to 0.92$)$ & 0.01 \\
\hline \multicolumn{7}{|c|}{ Consumption on heaviest day (1999-2008) } \\
\hline \multicolumn{7}{|l|}{ Model 1:* } \\
\hline Non-drinker & 70 & 1.00 (reference) & & 641 & 1.00 (reference) & \\
\hline Not in past 12 months $\dagger$ & 7 & $1.27(0.58$ to 2.76$)$ & 0.55 & 37 & 0.89 (0.64 to 1.24$)$ & 0.49 \\
\hline$<1$ occasion/month & 90 & 0.81 (0.59 to 1.10$)$ & 0.18 & 577 & 0.71 (0.63 to 0.79 ) & $<0.01$ \\
\hline 1-2 occasions/month & 46 & 0.57 (0.39 to 0.83 ) & $<0.01$ & 213 & 0.59 (0.51 to 0.69$)$ & $<0.01$ \\
\hline$>2$ occasions/month§ & 17 & 0.68 (0.40 to 1.16$)$ & 0.16 & 95 & 0.76 (0.61 to 0.94$)$ & 0.01 \\
\hline $0.1-1.5$ units & 45 & 0.50 (0.35 to 0.73$)$ & $<0.01$ & 466 & 0.67 (0.59 to 0.75$)$ & $<0.01$ \\
\hline $1.6-3.0$ units & 64 & 0.47 (0.34 to 0.67$)$ & $<0.01$ & 267 & $0.64(0.55$ to 0.74$)$ & $<0.01$ \\
\hline $3.1-4.5$ units & 20 & 0.51 (0.31 to 0.84$)$ & 0.01 & 39 & $0.60(0.44$ to 0.83$)$ & $<0.01$ \\
\hline$>4.5$ units & 38 & 0.60 (0.41 to 0.90$)$ & 0.01 & 36 & 0.63 (0.45 to 0.88$)$ & 0.01 \\
\hline \multicolumn{7}{|l|}{ Model 2: $¥$} \\
\hline Non-drinker & 52 & 1.00 (reference) & & 359 & 1.00 (reference) & \\
\hline Not in past 12 months $\uparrow$ & 6 & 1.18 (0.50 to 2.76$)$ & 0.71 & 20 & 1.16 (0.74 to 1.83 ) & 0.51 \\
\hline$<1$ occasion/month & 70 & $0.72(0.50$ to 1.03$)$ & 0.07 & 388 & 0.74 (0.64 to 0.86$)$ & $<0.01$ \\
\hline 1-2 occasions/month & 40 & 0.70 (0.46 to 1.06$)$ & 0.10 & 152 & 0.66 (0.54 to 0.80$)$ & $<0.01$ \\
\hline$>2$ occasions/month§ & 16 & 0.86 (0.49 to 1.52$)$ & 0.60 & 63 & 0.86 (0.66 to 1.13$)$ & 0.291 \\
\hline $0.1-1.5$ units & 39 & 0.67 (0.44 to 1.03$)$ & 0.07 & 305 & 0.72 (0.61 to 0.84$)$ & $<0.01$ \\
\hline $1.6-3.0$ units & 57 & 0.58 (0.39 to 0.86$)$ & 0.01 & 192 & 0.69 (0.58 to 0.83$)$ & $<0.01$ \\
\hline $3.1-4.5$ units & 18 & $0.56(0.32$ to 0.96$)$ & 0.04 & 28 & 0.55 (0.37 to 0.81$)$ & $<0.01$ \\
\hline$>4.5$ units & 34 & 0.60 (0.38 to 0.93$)$ & 0.02 & 27 & 0.59 (0.40 to 0.88$)$ & 0.01 \\
\hline \multicolumn{7}{|l|}{ Sample sizes (weekly): } \\
\hline Model 1 & & 6051 & & & 5562 & \\
\hline Model 2 & & 5444 & & & 4293 & \\
\hline \multicolumn{7}{|l|}{ Sample sizes (heaviest day): } \\
\hline Model 1 & & 11596 & & & 10267 & \\
\hline Model 2 & & 10323 & & & 7949 & \\
\hline
\end{tabular}

\section{${ }^{*}$ Adjusted for age.}

tParticipants who reported being current drinkers and also reported not having consumed alcohol within the 12 months before interview.

¥As model 1, plus adjustment for body mass index, economic activity, education, ethnicity, government office region, marital status, smoking status, and social class.

§Participants who reported an average annual frequency of $>2$ occasions/month but who reported not drinking in the week before interview.

based occasional drinking categories: those who reported consuming alcohol on less than one occasion a month and those who reported drinking alcohol on only one or two occasions a month. These "occasional drinkers" therefore represented infrequent consumers of alcohol. We excluded those who refused to answer or could not recall their frequency of consumption over the past year.

\section{Consumption on heaviest day}

We defined participants who reported drinking in the past year as current drinkers and asked whether they had also consumed alcohol in the past seven days. Of those who did, information was gathered on the types, quantities, and volumes of alcohol consumed on the heaviest drinking day in the week. Methods and conversion factors used to estimate use on the 


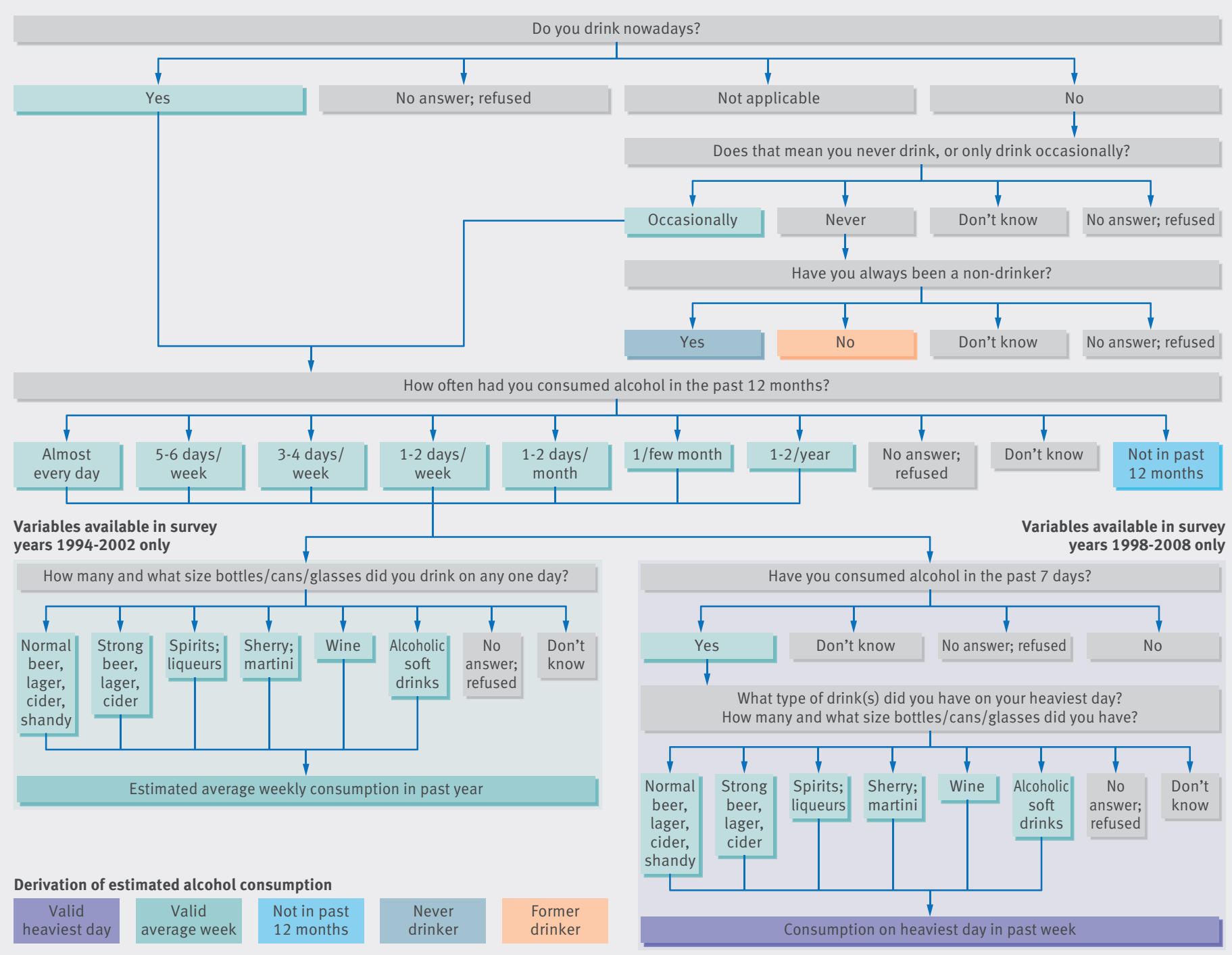

Fig 2 Routing of alcohol consumption questions in the Health Survey for England

heaviest day in the past week are detailed elsewhere. ${ }^{38} 39$

Consumption on the heaviest day was categorised into 1.5 unit increments $(\leq 1.5,>1.5-3.0,>3.0-4.5,>4.5$ units/day). Owing to the positive skewness of the heaviest day variable, whereby a few participants consumed alcohol at higher levels, we grouped those who reported consuming more than 4.5 units into a single category. Given that beneficial effects resulting from alcohol use have typically presented at levels below the 4.5 unit threshold, we did not consider such a categorisation of the highest consumption category as problematic for the purpose of these analyses.

We defined current drinkers who did not consume alcohol in the year before the interview and occasional drinkers as for the average weekly consumption variable, with the addition of a category denoting those with an average annual frequency of more than two occasions a month but who reported not drinking in the week before the interview. We excluded those who refused to answer or could not recall their frequency of consumption over the past year. Figure 2 outlines the derivation of both variables.

\section{Covariates}

To capture the effect of geographical and cultural differences in drinking behaviour, we included government office regions ${ }^{40}$ and ethnicity ${ }^{41}$ as covariates. For comparability across survey years, where definitions changed between surveys, we selected broad ethnic categories (white, black, Asian, Chinese, or other). This risked masking the heterogeneity of ethnic minority groups such as people of south Asian origin..$^{42}$ Education and occupational status have been identified as independent predictors of alcohol related mortality. ${ }^{43} 44$ Socioeconomic variables included education (national vocational qualification (NVQ) level 4-5, degree or equivalent; higher education below degree level; NVQ level 3 or general certificate of education (GCE) A level equivalent; NVQ level 2 or GCE O level equivalent; NVQ level 1, other grade equivalent or ungraded; foreign or other; no qualification; full time student), economic 
activity (employed, unemployed, retired, other economically inactive), and socioeconomic position (professional, managerial technical, skilled non-manual, skilled manual, semiskilled manual, unskilled manual, other, for example, armed forces).

Associations have also been identified between markers of social support and both drinking behaviour and mortality, ${ }^{45}$ including marital status ${ }^{46} 47$ and loneliness. ${ }^{48}$ Thus we included marital status as a covariate (single, married, separated, divorced, widowed).

Cigarette smoking status (never regular smoker, former smoker, $<10,10-19, \geq 20 /$ day) was selected given its differential distribution across consumption categories $^{49}$ and strong association with mortality. ${ }^{50}$ Finally, with possible associations between alcohol consumption and obesity, ${ }^{51}$ we also included body mass index $\left(<25.0,25.0-29.9, \geq 30.0 \mathrm{~kg} / \mathrm{m}^{2}\right)$.

\section{Statistical analyses}

The hierarchical multistage structure of the Health Survey for England sampling procedure produces a more geographically concentrated subset of participants than would be found using a simple random sampling method, introducing clustering that weakens statistical precision and underestimates variance. ${ }^{52}$ However, non-response weight and complex design variables were not introduced until 2003. We performed a sensitivity analysis to compare adjusted and non-unadjusted risk estimates according to the heaviest day use variable, restricted to years for which non-response weight and design variables were available (see supplementary tables 3 and 4). Dose-response relations according to adjusted and unadjusted data were broadly comparable, with only minor discrepancies in calculated risk estimates. Thus we made the decision to omit these variables in favour of utilising a broader number of survey years, increasing the number of participants included in the heaviest day analyses by extending the sample to include all survey years for which the heaviest day variable was available (1999-2008) and permitting the analysis of average weekly alcohol consumption over the previous year (1998-2002).

Missingness was generally low, at less than $0.2 \%$ for all but body mass index (weekly sample: $11.9 \%$; heaviest day sample: $12.5 \%$ ). Data on body mass index were missing for an assortment of reasons, including refusal, ineligibility through pregnancy or advanced age, or invalidity attributable to hairstyle or clothing. Those with missing data were more likely to be older, women, unqualified, full time students, retired, economically inactive, or single. Owing to small subgroup sample size, we recorded unemployed people aged more than 64 years as "other economically inactive" in both analytical samples $(\mathrm{n}=5)$.

For each alcohol consumption variable, we undertook proportional hazards analyses for each of the two age groups of interest. In all cases the first model reported age adjusted figures only, whereas the second model reported fully adjusted hazard ratios. We investigated the suitability of stratification by sex through the introduction of a sex-dose interaction term into each fully adjusted model. The interaction was highly significant in all cases $(\mathrm{P}<0.001)$, and so we reported sex specific models for each age group of interest. We also tested an age-dose interaction for each fully adjusted, age stratified sex specific model. This was statistically insignificant in all cases.

To examine the reasonableness of the proportional hazards assumption of each model, we used Stata's phtest command, ${ }^{53}$ regressing Schoenfeld residuals against time for each Cox model, and we assessed the log-log survival curves graphically. The proportionality assumption was met across all models. All analyses were conducted in Stata 13, with a significance threshold of less than 0.05 .

\section{Results}

Supplementary table 5 summarises the characteristics of the analytical samples. Older populations were more likely to be widowed, be retired, be former smokers, and have no qualifications. In terms of alcohol consumption, never and former drinking were more prevalent among older people, with alcohol use generally lower among women and older age-sex groups.

Tables 1 and 2 show the hazards of death compared with a conventional non-drinking category for both the weekly and the heaviest day use variables. In age adjusted models (model 1), weekly use and use on the heaviest day were protective at all levels and in all age groups except for women aged 50-64 years (table 2), where consumption of more than 20.0 units/week was insignificant $(\mathrm{P}=0.17)$.

Adjustment for covariates attenuated the degree of protection in most categories of weekly and heaviest day consumption (model 2). Among younger men, protection was apparent between 5.1 and 20.0 units/week and 0.1 and 1.5 units on the heaviest day, with peak protection of comparable magnitude identified at 15.1-20.0 (hazard ratio $0.51,95 \%$ confidence interval 0.32 to 0.82 ) and $0.1-1.5$ (0.50, 0.30 to 0.84$)$ units, respectively. Less protection was evident among older men, but with protective effects spread across a broader range of alcohol use categories. Peak protection was present at 15.1-20.0 units/week ( $0.69,0.53$ to 0.89$)$ and $>4.5$ units on the heaviest day (0.68, 0.57 to 0.82$)$.

After multivariable adjustment, protective associations were present among younger women at alcohol use between 0.1 and 15.0 units/week and > 1.5 units on the heaviest day. Peak protection was evident at a lower weekly use than in younger men, at 10.1-15.0 units $(0.48,0.29$ to 0.79$)$, but at a higher level according to the heaviest day variable (3.1-4.5 units, $0.56,0.32$ to 0.96 ). Peak protection among older women was present at the same level of use on the heaviest day (0.55, 0.37 to 0.81$)$ and at a weekly use comparable to older men (15.1-20.0 units/week, 0.67, 0.48 to 0.94 ).

In the fully adjusted model, in terms of occasional alcohol consumption, participants who reported consumption at a frequency of two or less drinking occasions a month consistently presented with borderline or signifcantly lower risks of all cause mortality compared with pooled non-drinkers in all age-sex groups on the weekly 
Table 3 | Relation between alcohol consumption and all cause mortality in men by age (never drinker referent category)

\begin{tabular}{|c|c|c|c|c|c|c|}
\hline \multirow[b]{2}{*}{ Alcohol intake } & \multicolumn{3}{|l|}{$50-64$ years } & \multicolumn{3}{|l|}{$\geq 65$ years } \\
\hline & No of deaths & Hazard ratio $(95 \% \mathrm{Cl})$ & P value & No of deaths & Hazard ratio $(95 \% \mathrm{Cl})$ & P value \\
\hline \multicolumn{7}{|c|}{ Weekly alcohol consumption (1998-2002) } \\
\hline \multicolumn{7}{|l|}{ Model 1:* } \\
\hline Never drinker & 20 & 1.00 (reference) & & 95 & 1.00 (reference) & \\
\hline Former drinker & 40 & 1.28 (0.75 to 2.19$)$ & 0.36 & 212 & $1.50(1.18$ to 1.92$)$ & $<0.01$ \\
\hline Not in past 12 months $\dagger$ & 2 & 1.02 (0.24 to 4.37$)$ & 0.98 & 19 & 1.53 (0.94 to 2.51$)$ & 0.09 \\
\hline$<1$ occasion/month & 53 & 0.77 (0.46 to 1.29$)$ & 0.33 & 268 & $1.07(0.85$ to 1.36$)$ & 0.55 \\
\hline 1-2 occasions/month & 48 & $0.69(0.41$ to 1.16$)$ & 0.17 & 180 & 0.97 (0.76 to 1.25$)$ & 0.83 \\
\hline $0.1-5.0$ units & 51 & $0.68(0.41$ to 1.14$)$ & 0.15 & 328 & 1.04 (0.83 to 1.31$)$ & 0.74 \\
\hline $5.1-10.0$ units & 72 & $0.63(0.38$ to 1.03$)$ & 0.07 & 328 & $0.83(0.66$ to 1.04$)$ & 0.11 \\
\hline 10.1-15.0 units & 58 & 0.61 (0.37 to 1.02$)$ & 0.06 & 226 & 1.01 (0.79 to 1.28$)$ & 0.94 \\
\hline 15.1-20.0 units & 34 & $0.48(0.27$ to 0.83$)$ & 0.01 & 108 & 0.78 (0.59 to 1.03$)$ & 0.08 \\
\hline$>20.0$ units & 195 & 0.81 (0.51 to 1.28$)$ & 0.36 & 413 & 0.96 (0.77 to 1.20$)$ & 0.71 \\
\hline \multicolumn{7}{|l|}{ Model 2: } \\
\hline Never drinker & 17 & 1.00 (reference) & & 73 & 1.00 (reference) & \\
\hline Former drinker & 37 & $0.93(0.52$ to 1.69$)$ & 0.82 & 144 & 1.18 (0.88 to 1.57$)$ & 0.27 \\
\hline Not in past 12 monthst & 1 & 0.51 (0.07 to 3.87) & 0.51 & 11 & $1.43(0.75$ to 2.71$)$ & 0.28 \\
\hline$<1$ occasion/month & 45 & 0.60 (0.33 to 1.07$)$ & 0.08 & 203 & 0.90 (0.68 to 1.19$)$ & 0.46 \\
\hline 1-2 occasions/month & 41 & 0.58 (0.32 to 1.05$)$ & 0.07 & 141 & 0.88 (0.66 to 1.18$)$ & 0.39 \\
\hline $0.1-5.0$ units & 44 & 0.72 (0.40 to 1.29$)$ & 0.27 & 249 & 0.92 (0.70 to 1.20$)$ & 0.54 \\
\hline $5.1-10.0$ units & 65 & 0.63 (0.36 to 1.11) & 0.11 & 263 & 0.78 (0.59 to 1.02 ) & 0.07 \\
\hline $10.1-15.0$ units & 52 & 0.62 (0.35 to 1.10$)$ & 0.10 & 188 & $0.92(0.69$ to 1.21$)$ & 0.54 \\
\hline $15.1-20.0$ units & 30 & 0.49 (0.26 to 0.91$)$ & 0.03 & 83 & 0.77 (0.56 to 1.06$)$ & 0.11 \\
\hline$>20.0$ units & 175 & 0.71 (0.42 to 1.21$)$ & 0.21 & 341 & 0.88 (0.67 to 1.14$)$ & 0.33 \\
\hline \multicolumn{7}{|c|}{ Consumption on heaviest day (1999-2008) } \\
\hline \multicolumn{7}{|c|}{ Model 1:* } \\
\hline Never drinker & 16 & 1.00 (reference) & & 90 & 1.00 (reference) & \\
\hline Former drinker & 41 & $1.34(0.75$ to 2.39$)$ & 0.32 & 219 & $1.78(1.39$ to 2.27$)$ & $<0.01$ \\
\hline Not in past 12 monthst & 6 & $2.76(1.08$ to 7.07$)$ & 0.03 & 26 & 1.53 (0.99 to 2.38$)$ & 0.05 \\
\hline$<1$ occasion/month & 57 & $0.84(0.48$ to 1.46$)$ & 0.54 & 357 & $1.35(1.07$ to 1.70$)$ & 0.01 \\
\hline 1-2 occasions/month & 44 & 0.65 (0.37 to 1.16$)$ & 0.14 & 216 & 1.15 (0.90 to 1.48$)$ & 0.25 \\
\hline$>2$ occasions/month§ & 20 & 0.80 (0.41 to 1.54$)$ & 0.51 & 130 & $1.31(1.00$ to 1.71$)$ & 0.05 \\
\hline $0.1-1.5$ units & 29 & $0.41(0.22$ to 0.75$)$ & $<0.01$ & 427 & $1.03(0.82$ to 1.29$)$ & 0.79 \\
\hline $1.6-3.0$ units & 88 & $0.59(0.35$ to 1.01$)$ & 0.06 & 454 & 0.98 (0.78 to 1.23$)$ & 0.89 \\
\hline $3.1-4.5$ units & 64 & 0.83 (0.48 to 1.44$)$ & 0.51 & 201 & 1.19 (0.92 to 1.52$)$ & 0.18 \\
\hline$>4.5$ units & 214 & 0.82 (0.49 to 1.37$)$ & 0.45 & 298 & 1.01 (0.79 to 1.28$)$ & 0.94 \\
\hline \multicolumn{7}{|l|}{ Model 2: } \\
\hline Never drinker & 12 & 1.00 (reference) & & 65 & 1.00 (reference) & \\
\hline Former drinker & 30 & 0.79 (0.40 to 1.58$)$ & 0.51 & 150 & 1.28 (0.95 to 1.73$)$ & 0.10 \\
\hline Not in past 12 months $t$ & 4 & $1.50(0.47$ to 4.77$)$ & 0.49 & 19 & 1.30 (0.78 to 2.19$)$ & 0.32 \\
\hline$<1$ occasion/month & 46 & 0.56 (0.29 to 1.09) & 0.09 & 269 & 1.07 (0.81 to 1.42$)$ & 0.62 \\
\hline 1-2 occasions/month & 39 & 0.56 (0.29 to 1.10$)$ & 0.09 & 167 & 1.02 (0.76 to 1.37 ) & 0.90 \\
\hline$>2$ occasions/month§ & 18 & 0.66 (0.31 to 1.40$)$ & 0.28 & 92 & 1.01 (0.73 to 1.40$)$ & 0.94 \\
\hline $0.1-1.5$ units & 25 & 0.43 (0.21 to 0.87$)$ & 0.02 & 322 & 0.92 (0.70 to 1.21$)$ & 0.55 \\
\hline $1.6-3.0$ units & 76 & 0.59 (0.31 to 1.11) & 0.10 & 351 & 0.86 (0.66 to 1.14$)$ & 0.29 \\
\hline $3.1-4.5$ units & 54 & 0.72 (0.37 to 1.37$)$ & 0.31 & 169 & 1.06 (0.79 to 1.43$)$ & 0.68 \\
\hline$>4.5$ units & 198 & 0.71 (0.38 to 1.31$)$ & 0.27 & 248 & 0.81 (0.61 to 1.08 ) & 0.15 \\
\hline \multicolumn{7}{|l|}{ Sample sizes (weekly): } \\
\hline Model 1 & & 5308 & & & 4447 & \\
\hline Model 2 & & 4876 & & & 3755 & \\
\hline \multicolumn{7}{|l|}{ Sample sizes (heaviest day): } \\
\hline Model 1 & & 10046 & & & 8365 & \\
\hline Model 2 & & 9155 & & & 7096 & \\
\hline
\end{tabular}

${ }^{*}$ Adjusted for age.

tParticipants who reported being current drinkers and also reported not having consumed alcohol within the 12 months before interview.

FAs model 1, plus adjustment for body mass index, economic activity, education, ethnicity, government office region, marital status, smoking status, and social class.

$\S$ Participants who reported an average annual frequency of $>2$ occasions/month but who reported not drinking in the week before interview.

consumption variable. For the heaviest day variable, statistically significant protective effects among occasional drinkers were specific to older women (table 2).

Tables 3 and 4 show the hazards after excluding former drinkers from the non-current referent category and compared with never drinkers. The case for omitting former drinkers from an abstention category is supported by their higher hazards compared with never drinkers. The attenuation or nullification of these hazards after adjustment for all covariates suggests that 
Table 4 | Relation between alcohol consumption and all cause mortality in women by age (never drinker referent category)

\begin{tabular}{|c|c|c|c|c|c|c|}
\hline \multirow[b]{2}{*}{ Alcohol intake } & \multicolumn{3}{|l|}{$50-64$ years } & \multicolumn{3}{|l|}{$\geq 65$ years } \\
\hline & No of deaths & Hazard ratio $(95 \% \mathrm{Cl})$ & Pvalue & No of deaths & Hazard ratio $(95 \% \mathrm{Cl})$ & P value \\
\hline \multicolumn{7}{|c|}{ Weekly alcohol consumption (1998-2002) } \\
\hline \multicolumn{7}{|l|}{ Model 1:* } \\
\hline Never drinker & 29 & 1.00 (reference) & & 353 & 1.00 (reference) & \\
\hline Former drinker & 43 & 1.94 (1.21 to 3.11$)$ & 0.01 & 300 & 1.34 (1.15 to 1.56$)$ & $<0.01$ \\
\hline Not in past 12 months $\dagger$ & 7 & 1.93 (0.84 to 4.40$)$ & 0.12 & 26 & 1.50 (1.01 to 2.24$)$ & 0.05 \\
\hline$<1$ occasion/month & 81 & 1.11 (0.72 to 1.69$)$ & 0.64 & 511 & 0.89 (0.78 to 1.02$)$ & 0.11 \\
\hline 1-2 occasions/month & 52 & 0.84 (0.53 to 1.32$)$ & 0.45 & 220 & 0.71 (0.60 to 0.84$)$ & $<0.01$ \\
\hline $0.1-5.0$ units & 66 & 0.77 (0.50 to 1.19$)$ & 0.24 & 364 & 0.74 (0.64 to 0.85$)$ & $<0.01$ \\
\hline $5.1-10.0$ units & 50 & $0.73(0.46$ to 1.16$)$ & 0.18 & 276 & $0.83(0.71$ to 0.97$)$ & 0.02 \\
\hline 10.1-15.0 units & 25 & 0.60 (0.35 to 1.03$)$ & 0.06 & 116 & $0.76(0.62$ to 0.94$)$ & 0.01 \\
\hline 15.1-20.0 units & 15 & 0.77 (0.41 to 1.43$)$ & 0.40 & 43 & 0.68 (0.49 to 0.93$)$ & 0.02 \\
\hline$>20.0$ units & 37 & 1.07 (0.66 to 1.74$)$ & 0.79 & 94 & 0.82 (0.66 to 1.03$)$ & 0.10 \\
\hline \multicolumn{7}{|l|}{ Model 2: $\neq$} \\
\hline Never drinker & 19 & 1.00 (reference) & & 205 & 1.00 (reference) & \\
\hline Former drinker & 37 & 1.79 (1.02 to 3.16$)$ & 0.04 & 181 & 1.23 (1.01 to 1.51$)$ & 0.04 \\
\hline Not in past 12 monthst & 6 & 1.63 (0.64 to 4.13) & 0.30 & 16 & $1.72(1.03$ to 2.88$)$ & 0.04 \\
\hline$<1$ occasion/month & 67 & 1.00 (0.59 to 1.67$)$ & 0.99 & 339 & 0.83 (0.70 to 0.99 ) & 0.04 \\
\hline 1-2 occasions/month & 42 & 0.92 (0.53 to 1.60$)$ & 0.77 & 160 & 0.74 (0.60 to 0.91$)$ & 0.01 \\
\hline $0.1-5.0$ units & 60 & 0.97 (0.57 to 1.65$)$ & 0.92 & 265 & 0.77 (0.64 to 0.92 ) & 0.01 \\
\hline $5.1-10.0$ units & 47 & 0.87 (0.50 to 1.50$)$ & 0.61 & 187 & 0.77 (0.63 to 0.94$)$ & 0.01 \\
\hline $10.1-15.0$ units & 22 & 0.68 (0.36 to 1.29$)$ & 0.24 & 89 & 0.85 (0.66 to 1.10$)$ & 0.22 \\
\hline $15.1-20.0$ units & 14 & 1.01 (0.50 to 2.05$)$ & 0.98 & 37 & 0.74 (0.52 to 1.06$)$ & 0.10 \\
\hline$>20.0$ units & 32 & 1.10 (0.61 to 1.98$)$ & 0.76 & 74 & 0.79 (0.60 to 1.03$)$ & 0.09 \\
\hline \multicolumn{7}{|c|}{ Consumption on heaviest day (1999-2008) } \\
\hline \multicolumn{7}{|c|}{ Model 1:* } \\
\hline Never drinker & 32 & 1.00 (reference) & & 346 & 1.00 (reference) & \\
\hline Former drinker & 38 & $1.28(0.80$ to 2.04$)$ & 0.31 & 295 & $1.33(1.14$ to 1.56$)$ & $<0.01$ \\
\hline Not in past 12 months ${ }^{\dagger}$ & 7 & $1.44(0.63$ to 3.26$)$ & 0.39 & 37 & $1.01(0.72$ to 1.41$)$ & 0.97 \\
\hline$<1$ occasion/month & 90 & $0.91(0.61$ to 1.37$)$ & 0.66 & 577 & 0.80 (0.70 to 0.92$)$ & $<0.01$ \\
\hline 1-2 occasions/month & 46 & 0.65 (0.41 to 1.02$)$ & 0.06 & 213 & 0.67 (0.56 to 0.79$)$ & $<0.01$ \\
\hline$>2$ occasions/month§ & 17 & 0.77 (0.43 to 1.39$)$ & 0.39 & 95 & $0.86(0.68$ to 1.07$)$ & 0.180 \\
\hline $0.1-1.5$ units & 45 & $0.57(0.36$ to 0.90$)$ & 0.02 & 466 & 0.76 (0.66 to 0.87$)$ & $<0.01$ \\
\hline $1.6-3.0$ units & 64 & 0.54 (0.35 to 0.82$)$ & $<0.01$ & 267 & 0.72 (0.61 to 0.85$)$ & $<0.01$ \\
\hline $3.1-4.5$ units & 20 & 0.58 (0.33 to 1.01$)$ & 0.06 & 39 & 0.68 (0.49 to 0.95$)$ & 0.02 \\
\hline$>4.5$ units & 38 & 0.68 (0.43 to 1.09 ) & 0.11 & 36 & 0.71 (0.50 to 1.00$)$ & 0.05 \\
\hline \multicolumn{7}{|l|}{ Model 2: } \\
\hline Never drinker & 19 & 1.00 (reference) & & 195 & 1.00 (reference) & \\
\hline Former drinker & 33 & 1.19 (0.67 to 2.11) & 0.55 & 164 & 1.14 (0.92 to 1.41$)$ & 0.22 \\
\hline Not in past 12 months $\dagger$ & 6 & 1.31 (0.52 to 3.31 ) & 0.57 & 20 & 1.23 (0.77 to 1.96$)$ & 0.38 \\
\hline$<1$ occasion/month & 70 & 0.80 (0.48 to 1.34$)$ & 0.40 & 388 & 0.79 (0.66 to 0.94$)$ & 0.01 \\
\hline 1-2 occasions/month & 40 & 0.78 (0.45 to 1.36$)$ & 0.38 & 152 & 0.70 (0.56 to 0.86$)$ & $<0.01$ \\
\hline$>2$ occasions/month§ & 16 & 0.96 (0.49 to 1.88$)$ & 0.90 & 63 & 0.92 (0.69 to 1.22$)$ & 0.55 \\
\hline $0.1-1.5$ units & 39 & 0.75 (0.43 to 1.31$)$ & 0.32 & 305 & 0.76 (0.63 to 0.91$)$ & $<0.01$ \\
\hline $1.6-3.0$ units & 57 & 0.65 (0.38 to 1.10$)$ & 0.11 & 192 & 0.73 (0.60 to 0.90$)$ & $<0.01$ \\
\hline $3.1-4.5$ units & 18 & 0.62 (0.32 to 1.20$)$ & 0.16 & 28 & 0.58 (0.39 to 0.87 ) & 0.01 \\
\hline$>4.5$ units & 34 & 0.66 (0.37 to 1.18) & 0.17 & 27 & 0.63 (0.42 to 0.95$)$ & 0.03 \\
\hline \multicolumn{7}{|l|}{ Sample sizes (weekly): } \\
\hline Model 1 & & 6051 & & & 5562 & \\
\hline Model 2 & & 5444 & & & 4293 & \\
\hline \multicolumn{7}{|l|}{ Sample sizes (heaviest day): } \\
\hline Model 1 & & 11596 & & & 10267 & \\
\hline Model 2 & & 10323 & & & 7949 & \\
\hline
\end{tabular}

\section{*Adjusted for age.}

tParticipants who reported being current drinkers and also reported not having consumed alcohol within the 12 months before interview.

¥As model 1, plus adjustment for body mass index, economic activity, education, ethnicity, government office region, marital status, smoking status, and social class.

§Participants who reported an average annual frequency of $>2$ occasions/month but who reported not drinking in the week before interview.

former drinkers may be disproportionally subject to a clustering of negative exposures.

Significant protective effects were apparent across a much narrower range of alcohol use categories after the exclusion of former drinkers from the referent category.
In fully adjusted data, protection among younger men was present only between 15.1 and 20.0 units/week (0.49, 0.26 to 0.91$)$ and $0.1-1.5$ units on the heaviest day (0.43, 0.21 to 0.87 ), whereas no significant protective association was evident at any level among older men 
and younger women drinkers, regardless of use category. Interestingly, despite the omission of former drinkers and application of broad covariate adjustment, alcohol consumption remained associated with a reduction in hazards among older women. Here, protective effects became restricted to lower levels of average weekly consumption ( $\leq 10$ units/week), with peak protection remaining present at 3.1-4.5 units on the heaviest day $(0.58,0.39$ to 0.87$)$. Additionally, among older women, protective effects remained among those who reported consumption at a frequency of two or less drinking occasions a month.

\section{Discussion}

The findings from this study suggest that beneficial associations typically identified between low intensity alcohol consumption and all cause mortality may, in part, be attributable to an inappropriate selection of a referent group and weak adjustment for confounders. Conventionally, research involving working age populations has alluded to a J-shaped relation between alcohol consumption and all cause mortality, with the most recent meta-analytic data indicating protective associations at 33.7 units/week or less among men and 15.9 units/week or less among women. ${ }^{10}$ In general, however, data specific to older populations are lacking, with one US study suggesting protection at less than 3.5 units/week for people aged 60-75 years. ${ }^{32}$

Aiming to develop the limited body of evidence concerning age specific associations between alcohol consumption and all cause mortality, age stratified analyses undertaken for this study support the assertion that risk profiles may differ according to age group, with protective associations apparently restricted to younger men (50-64 years) and older women ( $\geq 65$ years), compared with never drinkers and after adjustment for covariates (tables 3 and 4). Among younger men, the range of protective use was minimal, with a significantly favourable hazard rate present only among those who reported consuming 15.1-20.0 units/week (hazard ratio $0.49,95 \%$ confidence interval 0.26 to 0.91 ) or $0.1-1.5$ units on the heaviest day $(0.43,0.21$ to 0.87$)$. Sensitivity analyses indicated that protective effects were exacerbated among men when samples were limited to participants aged 50 years or more-that is, those at greater risk of cardiovascular disease. The range of protective use was broader but lower among older women, with significant reductions in hazards present at 10 units/week or less and at all levels of heaviest day use.

Within the context of mortality, age specific associations identified as part of this paper are therefore in conflict with the suggestion by the Royal College of Psychiatrists. ${ }^{30}$ Its guidelines recommend that alcohol consumption should be reduced for both sexes on the assumption of increased age related risk, to a maximum 11 units/week or 1.5 units/day for people aged 65 years or more.

There are two possible explanations for the lack of protective associations among most age specific and sex specific alcohol use categories compared with never drinkers. Firstly, it is possible that protective relations identified elsewhere among working age populations have occurred as products of inappropriate selection of a referent group, pooling among never drinkers a group of less healthy former drinkers known to be at high risk of mortality. ${ }^{14-16}$ This hypothesis is supported by our analyses, in which former drinkers commonly exhibited increased hazards before multivariate adjustment, with models compared with pooled non-drinkers portraying larger protective effects across a wider range of use than never drinkers only (tables 1-4). This mirrors findings from 54 mortality studies examined systematically, ${ }^{16}$ where the removal of former drinkers from referent categories resulted in an attenuation or complete nullification of reported protective effects. Through improved referent group selection, the analyses undertaken for this study may have better isolated the true effect of alcohol consumption on mortality.

A second explanation may be the more comprehensive selection of covariates over many existing studies, which have proved inconsistent and limited in their adjustment for confounding factors. For example, recent studies on alcohol related mortality have adjusted for age and smoking only, ${ }^{54}$ age, education, and smoking status only, ${ }^{55}$ and body mass index and smoking status only. ${ }^{56}$ Moreover, in a 2006 meta-analysis most data were found to be crude or age adjusted only, with protective effects present across a narrower range of alcohol consumption when restricted to studies reporting adjustment for confounders. It is possible that in the present study adjustment was sufficient for explaining the primary determinants of mortality, with alcohol consumption having little net impact overall.

Finally, attention should be drawn to the effect of selection biases when interpreting results from alcohol health studies, particularly where older populations are sampled and where those exhibiting ill health are excluded at baseline. For instance, although a 2013 analysis of European Prospective Investigation into Cancer and Nutrition (EPIC) study data identified protective associations between lifetime alcohol consumption and cardiovascular disease mortality at moderate levels of use in men and women, these beneficial effects were evident only among those who were free of prevalent disease at the time of enrolment. ${ }^{57}$ Such a finding suggests that protective effects commonly identified among existing studies may occur partly as a function of selection biases, such as the self selection of healthy participants. If so, rather than moderate alcohol consumption being directly involved in the attenuation of mortality risk, it may simply represent a lifestyle exposure specific to healthier people. ${ }^{58}$ In addition, although the removal of those with prevalent disease at baseline is a common means of attempting to avoid misclassification biases, such as misclassifying as light drinkers any former heavy drinkers whose consumption has recently decreased because of ill health, the removal of people who report poor health at baseline may only exacerbate the degree of selection bias. ${ }^{59}$ The effect of such biases should therefore be borne in mind when evaluating findings from alcohol health studies- 
particularly when seeking to extrapolate results to the population level.

Further age stratified dose-response analyses are required in other large prospective datasets to determine whether findings from the Health Survey for England are replicated elsewhere. Analyses need also to focus on the range of adverse health conditions experienced by older people.

\section{Strengths of this study}

In addition to the utilisation of an improved referent group and more comprehensive covariate adjustment compared with many existing studies, analyses undertaken for this paper are subject to two additional strengths. Firstly, exploring the applicability of age specific consumption guidelines within England, these analyses benefit from a focus on a representative sample of the English population, with adjustment for government office region. Generalisations based on existing studies may be complicated by their focus on non-English populations, with just five (15\%) of the studies selected in a meta-analysis ${ }^{10}$ having sampled cohorts covering the United Kingdom or its constituent countries. This is important given the possibility that health profiles and exposure to uncontrolled confounders may differ between regions, as highlighted by studies investigating relations between alcohol consumption and both homicide ${ }^{60}$ and unintentional injury, ${ }^{61}$ which have identified noticeable differences in mortality between countries. Additionally, significant disparities in alcohol consumption behaviour have been found even within nations. ${ }^{62}$

A further strength of this study was its explicit focus on people aged 65 years or more. Those beyond working age have been substantially under-represented by existing studies on alcohol related mortality. Given their differential drinking behaviours and physiology compared with people in younger age groups, the external validity of dose-response data drawn from working age populations is questionable when applied to older age groups.

We utilised two measures of alcohol use in an attempt to capture different drinking behaviours associated with the risk of all cause mortality: average weekly consumption and use on the heaviest drinking day in the week before interview. Results from these two measures were found to be complementary, both indicating that protective associations between alcohol consumption and mortality were largely specific to women aged 65 years or more (table 4). Restricting data to years for which both exposure variables were available (1999-2002), correlations between the variables excluding never and former drinking categories were strong within age-sex strata $(r=0.57$ to 0.65 , $\mathrm{P}<0.001)$

Finally, we linked and pooled data from up to 10 large scale population based surveys representative of the non-institutionalised English population. Findings from this study are therefore likely to have sound external validity for English residents in middle and older age.

\section{Limitations of this study}

Estimates of alcohol consumption depended on self reported data, which can be influenced by several factors, including social context and cultural norms, with evidence suggesting that people may alter their response according to perceived social desirability. ${ }^{63}$ Accordingly, higher levels of alcohol consumption may have been under-reported, leading to a misclassification of heavier drinkers into lower consumption categories. Such a misclassification may have positively biased the coefficients of lower consumption categories, attenuating any protective effects present among appropriately defined light drinkers. Additionally, heavy drinkers particularly may have opted not to participate in the survey. This combination of potential selection and reporting biases may explain the absence of increased risk among participants within categories of higher alcohol use, as typically identified in meta-analyses.

A further limitation lies in the reliability of participant recall. According to data from the US National Alcohol Survey, ${ }^{64} 52.9 \%$ of participants who declared themselves as never drinkers in 1992 had reported drinking in a previous survey. Similar results have also been found with data from the 1958 British Birth Cohort Study, where $67 \%$ of self defined never drinkers reported drinking in a previous wave, ${ }^{65}$ with a figure of $53 \%$ identified based on follow-up data from the US National Alcohol Survey. Such reporting errors introduce uncertainty about the reliability of associations based on self reported estimates of consumption.

Aside from problems of reliability, the suitability of using referent categories for never drinking is subject to ongoing debate. Although the exclusion of former drinkers from referent categories helped omit less healthy people and reduce the artificial inflation of protective effects among current drinkers, some concern remains about the appropriateness of a never drinking referent category in populations where drinking is normative. It has been found, for instance, that participants who reported illness over consecutive waves of two British birth cohort studies were more likely to have remained non-drinkers over the same period. ${ }^{66}$ Taken together, it seems that more than half of never drinkers may be misclassified and that a proportion of correctly defined never drinkers may represent an atypical population subgroup subject to poorer health than the general population in a manner akin to former drinkers. As a consequence, some have recommended the use of occasional drinkers as a more appropriate referent category, ${ }^{64}{ }^{67}$ although precise definitions differ between publications-ranging, for example, from 1-11 drinks a year (0.02-0.21 drinks/month) ${ }^{16}$ to $1-2$ drinks a month. ${ }^{68}$ When we tested several definitions (see supplementary table 6), the selection of occasional drinkers as a referent category was found to near consistently remove all protective dose-response effects.

In terms of mortality ascertainment, deaths documented by 31 March 2011 may not represent the true number of deaths during follow-up. Firstly, there may have been a delay between a death and that death being 
documented, leading to an underestimation of mortality among the cohort. With a similar effect, participants who moved from the United Kingdom and subsequently died abroad will have been coded as censored except in instances where a host nation informed the National Health Service central register. However, the impact of this was likely to be small.

Analyses did not adjust for survey design variables capable of accounting for the clustered and hierarchical nature of the sampling procedure. Additionally, some degree of unequal selection probability was likely to have been present, potentially giving undue influence to any oversampled population subgroups. However, sensitivity analyses indicated that the effect of these on the study findings was likely to be small.

With conventional longitudinal statistical methods operating under the assumption that baseline use remains stable over time, employing repeated measures will prove beneficial. Of the few studies to have utilised repeated measures of alcohol use, substantial variability in drinking behaviours were identified over time, 6970 suggesting that established approaches to risk estimation are insufficient for modelling the complexity of temporal variations in alcohol consumption and their effect on the risk of incident morbidity and mortality. The use of growth mixture models alongside repeated measures will permit the identification and analysis of heterogeneous drinking trajectories, potentially providing a better modelling of total alcohol use over the life course and the association between specific consumption trajectories and risk of disease.

\section{Conclusions}

Findings indicate that beneficial associations between alcohol consumption and all cause mortality may be attributable in part to inappropriate referent group selection and weak adjustment for confounders. Selection biases may also play a part. Compared with never drinkers and within the context of all cause mortality, age stratified analyses undertaken within this study suggest that beneficial dose-response relations are largely specific to women drinkers aged 65 years or more, with little to no protection present in other agesex groups. However, it is possible that the impact of selection biases across age-sex strata may explain these protective associations. Regardless of whether protective associations between alcohol consumption and mortality are real, however, temporal variability in alcohol consumption appears such that longitudinal analyses utilising repeated measures of use to investigate alcohol health relations would seem prudent. Future research should seek to move toward statistical techniques capable of analysing complex heterogeneous drinking trajectories, such as growth mixture models.

Contributors: CSK conceived the study and completed analyses with advice from JPB. CSK and JPB interpreted these data and drafted the paper. ES acquired the data. NC and ES created the custom dataset comprising pooled data from multiple Health Surveys for England and follow-up through linkage to national mortality registration data. NC and ES both contributed to revisions of the paper. CSK and JPB are the guarantors.
Funding: The Health Survey for England was initially funded by the Department of Health. Since April 2005, the Health Survey for England has been funded by the NHS Information Centre for Health and Social Care. The developers and funders of the Health Survey for England do not bear any responsibility for the analyses or interpretations presented here. The views expressed in this article are those of the authors and do not necessarily reflect those of the funders. CSK is supported by a three year PhD studentship from the European Research Council.

Competing interests: All authors have completed the ICMJE uniform disclosure form at www.icmje.org/coi_disclosure.pdf and declare: no support from any organisation for the submitted work; no financial relationships with any organisation that might have an interest in the submitted work in the previous three years; no other relationships or activities that could appear to have influenced the submitted work.

Ethical approval: The Health Survey for England 1998-99 was approved by London North Thames multicentre research ethics committee (MREC/97/2/9, MREC/98/2/89), the Health Survey for England $2000-07$ by the London multicentre research ethics committee (MREC/99/2/91; MREC/00/2/81, MREC/01/2/82, MREC/02/2/72, MREC/03/2/97, 04/MRE02/50, 05/MREC02/47, 06/ MRE02/62), and the Health Survey for England 2008 by Oxford A (07/ H0604/102). Each participant gave verbal consent to be interviewed for the survey.

Data sharing: Access to Health Survey for England data should be made through the UK Data Service (www.ukdataservice.ac.uk), and requests for mortality linkage made through NatCen (www.natcen. ac.uk).

Transparency: The lead authors (CSK and JPB) affirm that this manuscript is an honest, accurate, and transparent account of the study being reported; that no important aspects of the study have been omitted; and that any discrepancies from the study as planned have been explained.

This is an Open Access article distributed in accordance with the Creative Commons Attribution Non Commercial (CC BY-NC 4.0) license, which permits others to distribute, remix, adapt, build upon this work non-commercially, and license their derivative works on different terms, provided the original work is properly cited and the use is non-commercial. See: http://creativecommons.org/licenses/ by-nc/4.0/.

1 Rehm J, Baliunas D, Borges GL, Graham K, Irving H, Kehoe T, et al. The relationship between different dimensions of alcohol consumption and burden of disease - an overview. Addiction 2010:105:817-43.

2 British Medical Association. Alcohol misuse: tackling the UK epidemic. BMA, 2008.

3 Department of Health. The cost of alcohol harm to the NHS in England. DoH, 2008.

4 National Treatment Agency for Substance Misuse. Alcohol treatment in England 2011-12. NTA, 2013.

5 HM Treasury. Budget 2012. HC 1853. Stationery Office, 2012.

6 Prime Minister's Strategy Unit. Strategy Unit Alcohol Harm Reduction Project: interim analytical report. Cabinet Office, 2003.

7 Lister G. Evaluating social marketing for health-the need for consensus. Proceedings of the National Social Marketing Centre, 2007.

8 Holman CD, English DR, Milne E, Winter MG. Meta-analysis of alcohol and all-cause mortality: a validation of NHMRC recommendations. Med I Aust 1996:164:141-5.

9 House of Commons Science and Technology Committee. Alcohol guidelines. Eleventh report of session 2010-12. Vol 1: report, together with formal minutes, oral and written evidence. Stationery Office, 2012

10 Di Castelnuovo A, Costanzo S, Bagnardi V, Donati MB, Iacoviello L, de Gaetano G. Alcohol dosing and total mortality in men and women: an updated meta-analysis of 34 prospective studies. Arch Intern Med 2006;166:2437-45.

11 Corrao G, Bagnardi V, Zambon A, La Vecchia C. A meta-analysis of alcohol consumption and the risk of 15 diseases. Prev Med 2004;38:613-9.

12 Ronksley PE, Brien SE, Turner BJ, Mukamal KJ, Ghali WA. Association of alcohol consumption with selected cardiovascular disease outcomes: a systematic review and meta-analysis. BMJ 2011;342:d671

13 Office for National Statistics. Death registrations summary tables, England and Wales, 2013. ONS, 2014.

14 Emberson JR, Bennett DA. Effect of alcohol on risk of coronary heart disease and stroke: causality, bias, or a bit of both? Vasc Health Risk Manag 2006;2:239-49.

15 Shaper AG. Alcohol and mortality: a review of prospective studies. $\mathrm{Br}$ Addict 1990;85:837-47.

16 Fillmore KM, Stockwell T, Chikritzhs T, Bostrom A, Kerr W, et al. Moderate alcohol use and reduced mortality risk: systematic error in 
prospective studies and new hypotheses. Ann Epidemiol 2007;17(5 Suppl):S16-23.

17 Wannamethee G, Shaper AG. Men who do not drink. Int J Epidemiol 1988;17:307-16.

18 Graham K. Alcohol abstention among older adults: reasons for abstaining and characteristics of abstainers. Addiction Res 1998;6:473-87.

19 Tsubono Y, Yamada S, Nishino Y, Tsuji I, Hisamichi S. Choice of comparison group in assessing the health effects of moderate alcohol consumption. JAMA 2001;286:1177-8.

20 Health and Social Care Information Centre. Health Survey for England-2012: trend tables. HSCIC, 2013.

21 Meier P, Seitz HK. Age, alcohol metabolism and liver disease. Curr Opin Clin Nutr Metab Care 2008;11:21-6.

22 Dufour MC, Archer L, Gordis E. Alcohol and the elderly. Clin Geriatr Med 1992:8:127-41.

23 Gärtner U, Schmier M, Bogusz M, Seitz HK. Blood alcohol concentrations after oral alcohol administration-effect of age and sex. Z Gastroenterol 1996;34:675-9.

24 Lucey MR, Hill EM, Young JP, Demo-Dananberg L, Beresford TP. The influences of age and gender on blood ethanol concentrations in healthy humans. I Stud Alcohol 1999;60:103-10.

25 Fink A, Hays RD, Moore AA, Beck JC. Alcohol-related problems in older persons. Determinants, consequences, and screening. Arch Intern Med 1996;156:1150-6.

26 Falaschetti E, Malbut K, Primatesta P. The general health of older people and their use of health services. Stationery Office, 2002.

27 Forster LE, Pollow R, Stoller EP. Alcohol use and potential risk for alcohol-related adverse drug reactions among community-based elderly. J Community Health 1993;18:225-39.

28 Alcohol Concern. Alcohol misuse among older people.Acquire: Alcohol Concern's Quarterly Information and Research Bulletin. London: Alcohol Concern, 2002.

29 Health and Social Care Information Centre Statistics on alcohol: England, 2012. HSCIC, 2012. www.hscic.gov.uk/pubs/alcohol12.

30 Crome I, Dar K, Janikiewicz S, Rao T, Tarbuck A. Our invisible addicts: first report of the Older Persons' Substance Misuse Working Group of the Royal College of Psychiatrists. RCPsych, 2011.

31 Goldberg RJ, Burchfiel CM, Reed DM, Wergowske G, Chiu D. A prospective study of the health effects of alcohol consumption in middle-aged and elderly men. The Honolulu Heart Program. Circulation 1994;89:651-9.

32 Rehm J, Sempos CT. Alcohol consumption and all-cause mortality. Addiction 1995:90:471-80

33 Rimm EB, Williams P, Fosher K, Criqui M, Stampfer MJ. Moderate alcohol intake and lower risk of coronary heart disease: meta-analysis of effects on lipids and haemostatic factors. BM/1999:319:1523-8.

34 Xin X, He J, Frontini MG, Ogden LG, Motsamai OI, Whelton PK. Effects of alcohol reduction on blood pressure: a meta-analysis of randomized controlled trials. Hypertension 2001;38:1112-7.

35 Britton A, McPherson K. Mortality in England and Wales attributable to current alcohol consumption. J Epidemiol Community Health 2001;55:383-8

36 Mindell J, Biddulph JP, Hirani V, Stamatakis E, Craig R, Nunn S, et al. Cohort profile: the Health Survey for England. Int J Epidemiol 2012;41:1585-93.

37 Erens B. Alcohol consumption. In: Sproston K, Primatesta P, eds Health Survey for England 2002: The Health of Children and Young People. NHS Information Centre for Health and Social Care, 2003.

38 Fuller E. Adult alcohol consumption. In Craig R, Mindell J, Hirani V, eds. Health Survey for England 2008, Volume 1: Physical activity and fitness. NHS Information Centre for Health and Social Care 2009.

39 Goddard E. Estimating alcohol consumption from survey data: improved method of converting volume to units. Office for National Statistics, 2007.

40 Office for National Statistics Geography GIS and Mapping Unit. Regions and their constituent counties/unitary authorities as at 2011. ONS, 2011.

41 Hurcombe R, Bayley M, Goodman A. Ethnicity and alcohol: a review of the UK literature. Joseph Rowntree Foundation, 2010

42 Bhopal R, Unwin N, White M, Yallop J, Walker L, Alberti KG, et al. Heterogeneity of coronary heart disease risk factors in Indian, Pakistani, Bangladeshi, and European origin populations: cross sectional study. BM/ 1999;319:215-20.

43 Mäkelä P. Alcohol-related mortality as a function of socio-economic status. Addiction 1999;94:867-86.

44 Mäkelä P. Contribution of deaths related to alcohol use to socioeconomic variation in mortality: register based follow up study. $B M / 1997 ; 315: 211$
45 Murray RP, Rehm J, Shaten J, Connett JE. Does social integration confound the relation between alcohol consumption and mortality in the Multiple Risk Factor Intervention Trial (MRFIT)? I Stud Alcohol 1999;60:740-5.

46 Prescott CA, Kendler KS. Associations between marital status and alcohol consumption in a longitudinal study of female twins. I Stud Alcohol 2001;62:589-604

47 Stack S, Wasserman I. Marital status, alcohol consumption, and suicide: an analysis of national data. J Marriage Fam 1993:55:1018-24.

48 Luo Y, Hawkley LC, Waite LJ, Cacioppo JT. Loneliness, health, and mortality in old age: a national longitudinal study. Soc Sci Med 2012;74:907-14.

49 Howie EK, Sui X, Lee DC, Hooker SP, Hébert JR, Blair SN. Alcohol consumption and risk of all-cause and cardiovascular disease mortality in men. J Aging Res 2011;2011:805062.

50 Doll R, Peto R, Boreham I, Sutherland I. Mortality in relation to smoking: 50 years' observations on male British doctors. BMJ 2004;328:1519.

51 Sayon-Orea C, Martinez-Gonzalez MA, Bes-Rastrollo M. Alcoho consumption and body weight: a systematic review. Nutr Rev 2011;69:419-31

52 Rafferty A. Introduction to complex sample design in UK Government surveys. ESDS Government, 2011.

53 StataCorp. Survival analysis and epidemiological tables reference manual, release 13. College Station. StataCorp LP, 2013.

54 Doll R, Peto R, Boreham J, Sutherland I. Mortality in relation to alcoho consumption: a prospective study among male British doctors. Int J Epidemiol 2005;34:199-204.

55 Pednekar MS, Sansone G, Gupta PC. Association of alcohol, alcohol and tobacco with mortality: findings from a prospective cohort study in Mumbai (Bombay), India.Alcohol 2012;46:139-46.

56 Nakamura Y, Ueshima H, Kadota A, Hozawa A, Okamura T, Kadowaki S, et al. Alcohol intake and 19-year mortality in diabetic men: NIPPON DATA80. Alcohol 2009;43:635-41.

57 Bergmann MM, Rehm J, Klipstein-Grobusch K, Boeing H, Schütze M, Drogan $\mathrm{D}$, et al. The association of pattern of lifetime alcohol use and cause of death in the European Prospective Investigation into Cancer and Nutrition (EPIC) study. Int J Epidemiol 2013;42:1772-90.

58 Stockwell T, Chikritzhs T. Commentary: another serious challenge to the hypothesis that moderate drinking is good for health? Int Epidemiol 2013;42:1792-4

59 Marschner IC, Simes RJ, Keech A. Biases in the identification of risk factor thresholds and J-curves. Am I Epidemiol 2007;166:824-31.

60 Rossow I. Alcohol and homicide: a cross-cultural comparison of the relationship in 14 European countries. Addiction 2001;96(Suppl 1):S77-92.

61 Skog OJ. Alcohol consumption and overall accident mortality in 14 European countries. Addiction 2001;96(Suppl 1):S35-47.

62 Shelton N, Savell E. The geography of binge drinking: the role of alcohol-related knowledge, behaviours and attitudes. Results from the Health Survey for England 2007. Health Place 2011;17:784-92.

63 Davis CG, Thake J, Vilhena N. Social desirability biases in self-reported alcohol consumption and harms. Addict Behav 2010;35:302-11.

64 Rehm J, Irving H, Ye Y, Kerr WC, Bond J, Greenfield TK. Are lifetime abstainers the best control group in alcohol epidemiology? On the stability and validity of reported lifetime abstention. Am J Epidemiol 2008:168:866-71.

65 Caldwell TM, Rodgers B, Power C, Clark C, Stansfeld SA. Drinking histories of self-identified lifetime abstainers and occasional drinkers: findings from the 1958 British Birth Cohort Study. Alcohol Alcohol 2006:41:650-4.

66 Ng Fat L, Cable N, Marmot MG, Shelton N. Persistent long-standing illness and non-drinking over time, implications for the use of lifetime abstainers as a control group. J Epidemiol Community Health 2014;68:71-7.

67 Shaper AG, Wannamethee G, Walker M. Alcohol and mortality in British men: explaining the U-shaped curve. Lancet 1998;2:1267-73.

68 Shaper A, Wannamethee S. Alcohol intake and mortality in middle aged men with diagnosed coronary heart disease. Heart 2000;83:394-9.

69 Sher KJ, Jackson KM, Steinley D. Alcohol use trajectories and the ubiquitous cat's cradle: cause for concern? J Abnorm Psychol 2011;120:322-35

70 Britton A, Marmot MG, Shipley MJ. How does variability in alcohol consumption over time affect the relationship with mortality and coronary heart disease? Addiction 2010;105:639-45.

(C) BMJ Publishing Group Ltd 2015 